\title{
A Study to Evaluate the Role of Hypokalemia in Acute Myocardial Infarction Patients: A Prospective Hospital Based Study
}

\author{
Kantilal Meghwal ${ }^{1}$ \\ ${ }^{1}$ Department of Medicine, Government District Hospital, Dungarpur, Rajasthan, India.
}

\section{Abstract}

Background: Congestive heart failure (CHF) is a common comorbidity following acute myocardial infarction (AMI), and CHF complicating AMI has an unfavourable outcome. Several studies have demonstrated a relationship between low serum potassium levels and the risk of ventricular arrhythmias in patients with acute myocardial infarction (AMI). Hence; under the light of above obtained results, we planned the present study to assess the role of hypokalemia in AMI patients. Subjects and Methods: A total of 38 AMI patients and 38 healthy controls were included in the present study. Only patients within the age group of 20 years to 60 years were included. Detailed demographic and clinical data of all the subjects was obtained. Fresh blood samples were obtained from all the subjects and were sent to the laboratory for assessment. Serum potassium levels were analyzed by using an auto-analyzer. Results: Mean serum potassium levels among the subjects of the AMI group was found to be $85.6 \mathrm{mmol} / \mathrm{L}$, which was significantly lower than that of mean serum potassium levels of the subjects of the control group, which was found to be $93.4 \mathrm{mmol} / \mathrm{L}$. 20 subjects of the AMI group had hypokalemia. Therefore, prevalence of hypokalemia among the subjects of the AMI group was 52.6\%. Conclusion: AMI patients are significantly associated with hypokalemia, thereby, indicating its role in the pathogenesis of the disease.

Keywords: Acute myocardial infarction, Hypokalemia, Potassium.

Corresponding Author: Dr. Kantilal Meghwal, Department of Medicine, Government District Hospital, Dungarpur, Rajasthan, India.

Received: March 2019

Accepted: March 2019

Introduction

Congestive heart failure (CHF) is a common comorbidity following acute myocardial infarction (AMI), and $\mathrm{CHF}$ complicating AMI has an unfavourable outcome. Water and sodium retention are the key pathophysiological events leading to 'congestion' in CHF. It is now clear that CHF is the result of a systemic neurohormonal response involving the heart, kidneys, and vasculature. ${ }^{[1-3]}$

Potassium is the major cation inside the cells and is hugely important for regulating heartbeat and muscle function. It forms the other half of the electrical pump that keeps electrolytes in balance and allows conductivity between the cells, also making potassium a critical part of neuron transmission. ${ }^{[4-6]}$

Several studies have demonstrated a relationship between low serum potassium levels, usually less than $3.5 \mathrm{mEq} / \mathrm{L}$, and the risk of ventricular arrhythmias in patients with acute myocardial infarction (AMI).1-7 On the basis of these studies, experts and professional societies have recommended maintaining potassium levels between 4.0 and $5.0 \mathrm{mEq} / \mathrm{L},{ }^{[8,9]}$ or even 4.5 to $5.5 \mathrm{mEq} / \mathrm{L}, 10$ in $\mathrm{AMI}$ patients. ${ }^{[7-9]}$

Hence; under the light of above obtained results, we planned the present study to assess the role of hypokalemia in AMI patients.

\section{Subjects and Methods}

The present study was commenced in the department of general medicine of Government District Hospital, Dungarpur, Rajasthan, India. It included assessment of role of hypokalemia in AMI patients. A total of 38 AMI patients and 38 healthy controls were included in the present study. Only patients within the age group of 20 years to 60 years were included. Detailed demographic and clinical data of all the subjects was obtained. Fresh blood samples were obtained from all the subjects and were sent to the laboratory for assessment. Serum potassium levels were analyzed by using an auto-analyzer. All the results were recorded in Microsoft excel sheet and were analyzed by SPSS software. Chi-square test was used for assessment of level of significance.

\section{Results}

A total of 76 subjects were analyzed in the present study, among which, 38 belonged to the AMI group, while the remaining 38 belonged to the control group. Mean age of the subjects of the AMI group was 48.9 years, while mean age of the subjects of the control group was 47.2 years. There were 20 males and 18 females in the AMI group, while there were 22 males and 16 females in the control 
group. Mean serum potassium levels among the subjects of the AMI group was found to be $85.6 \mathrm{mmol} / \mathrm{L}$, which was significantly lower than that of mean serum potassium levels of the subjects of the control group, which was found to be $93.4 \mathrm{mmol} / \mathrm{L}$. 20 subjects of the AMI group had hypokalemia. Therefore, prevalence of hypokalemia among the subjects of the AMI group was 52.6\%.

\section{Table 1: Demographic data}

Table 1: Demographic data
\begin{tabular}{|l|l|l|}
\hline Parameter & AMI group & Control group \\
\hline Mean age & 48.9 & 47.2 \\
\hline Males & 20 & 22 \\
\hline Females & 18 & 16 \\
\hline Mean BMI $(\mathrm{Kg} / \mathrm{m} 2)$ & 26.5 & 25.7 \\
\hline
\end{tabular}

Table 2: Comparison of mean potassium levels among the two study groups

\begin{tabular}{|l|l|l|l|}
\hline Parameter & AMI group & Control group & p- value \\
\hline $\begin{array}{l}\text { Serum potassium } \\
\text { levels (mmol/L) }\end{array}$ & 85.6 & 93.4 & 0.02 \\
\hline
\end{tabular}

Table 3: Prevalence of hypokalemia among the subjects of the AMI group

\begin{tabular}{|l|l|l|}
\hline Parameter & Number of subjects & Percentage of subjects \\
\hline Hypokalemia & 20 & 52.6 \\
\hline
\end{tabular}

\section{Discussion}

Fluctuations in potassium levels are common in patients with AMI and CHF; therefore, is a single potassium level the best predictor for mortality? Although potassium predicts mortality, does it cause death per se? It is indeed possible that potassium levels are a marker for worse disease rather a mechanism of disease. ${ }^{[7-9]}$

A total of 76 subjects were analyzed in the present study, among which, 38 belonged to the AMI group, while the remaining 38 belonged to the control group. Mean age of the subjects of the AMI group was 48.9 years, while mean age of the subjects of the control group was 47.2 years. There were 20 males and 18 females in the AMI group, while there were 22 males and 16 females in the control group. Shlomai G et al evaluated whether different levels of serum potassium, within the normal range, are associated with worse outcomes. The study comprised 1277 patients with AMI and normal-range admission potassium levels (3.5-5.2 $\mathrm{mEq} / \mathrm{L})$, who were enrolled and prospectively followed up in the Acute Coronary Syndrome Israeli Survey between 2010 and 2013. Patients were divided into 4 quartiles based on admission potassium levels; "normallow" ( $\mathrm{K} \geq 3.5$ and $\mathrm{K} \leq 3.9)$, "normal-moderate" $(\mathrm{K}>3.9$ and $\mathrm{K} \leq 4.18)$, "normal-high" $(\mathrm{K}>4.18$ and $\mathrm{K} \leq 4.45)$, and "normal-very high" $(K>4.45$ and $K \leq 5.2)$. We analyzed the association between admission serum potassium levels and 7 days in-hospital complication rates, and 30-day and 1-year all-cause mortality rates. Patients with "normal-very high" potassium displayed increased frequency of baseline clinical risk factors and experienced a higher rate of acute kidney injury during hospitalization compared with the "normal-low" group (7.7\% vs $2.4 \% ; \mathrm{P}=0.002)$. However, the rate of in-hospital ventricular arrhythmias was similar across the range of admission potassium levels (overall $\mathrm{P}=$ 0.26), Multivariate analysis showed that compared with "low-normal" potassium values, patients with "normal-very high" potassium levels experienced increased risk for 30days (adjusted hazard ratio 2.88, 95\% confidence interval 1.05-7.87, $\mathrm{P}=0.039$ ) and 1-year all-cause mortality (adjusted hazard ratio 1.98, 95\% confidence interval $1.05-$ $3.75, \mathrm{P}=0.034)$. In patients admitted with AMI, admission serum potassium levels of 4.45 to $5.2 \mathrm{mEq} / \mathrm{L}$ are not associated with in-hospital ventricular arrhythmias, but are associated with increased short and long-term mortality.10 In the present study, mean serum potassium levels among the subjects of the AMI group was found to be 85.6 $\mathrm{mmol} / \mathrm{L}$, which was significantly lower than that of mean serum potassium levels of the subjects of the control group, which was found to be $93.4 \mathrm{mmol} / \mathrm{L}$. 20 subjects of the AMI group had hypokalemia. Therefore, prevalence of hypokalemia among the subjects of the AMI group was 52.6\%. Colombo $\mathrm{MG}$ et al examined the association between serum potassium concentration (SPC) and longterm mortality following AMI in patients recruited from a population-based registry. Included in the study were 3347 patients with AMI aged 28-74 years consecutively hospitalized between 1 January 2000 and 31 December 2008 and followed up until 31 December 2011. Patients were categorized into five SPC groups $(<3.5,3.5$ to $<4.0$, 4.0 to $<4.5,4.5$ to $<5.0$, and $\geq 5.0 \mathrm{mEq} / \mathrm{l})$. The outcome of the study was all-cause mortality. In our study population, 249 patients $(7.4 \%)$ had a low SPC $(<3.5 \mathrm{mEq} / \mathrm{l})$ and 134 $(4.0 \%)$ patients had a high SPC $(\geq 5.0 \mathrm{mEq} / \mathrm{l})$. Patients with SPC of $\geq 5.0 \mathrm{mEq} / 1$ had the highest long-term mortality $(29.9 \%)$ and in the adjusted model, their risk of dying was significantly increased (HR 1.46, 95\% CI 1.03 to 2.07) compared to patients with SPC between 4.0 and $<4.5 \mathrm{mEq} / \mathrm{l}$. Analyses of increasing observation periods showed a trend towards a higher risk of dying in patients with SPC between 4.5 and $<5.0 \mathrm{mEq} / 1$. An admission $\mathrm{SPC}$ of $\geq 5.0 \mathrm{mEq} / 1 \mathrm{might}$ be associated with an increased mortality risk in patients with AMI. ${ }^{[11]}$

\section{Conclusion}

Under the light of above obtained results, the authors concluded that AMI patients are significantly associated with hypokalemia, thereby, indicating its role in the pathogenesis of the disease. However; further studies are recommended.

\section{References}

1. Choi JS, Kim YA, Kim HY, Oak CY, Kang YU, Kim CS, Bae EH, Ma SK, Ahn YK, Jeong MH, Kim SW. Relation of serum potassium level to long-term outcomes in patients with acute myocardial infarction. Am J Cardiol 2014;113:1285-1290.

2. Cohn JN, Kowey PR, Whelton PK, Prisant LM. New guidelines for potassium replacement in clinical practice: a contemporary review by the National Council on Potassium in Clinical Practice. Arch Intern Med. 2000;160(16):2429-243610979053

3. Xianghua F, Peng Q, Yanbo W, Shigiang L, Weize F, Yunfa J. The relationship between hypokalemia at the early stage of acute 
myocardial infarction and malignant ventricular arrhythmia. Heart. 2010;96:196.

4. Kast DL. Prevalence of hypokalaemia in acute myocardial infarction patients. Int J Contem Med Surg Radiol. 2018;3(2):B41-B43.

5. Shiyovich A, Gilutz H, Plakht Y. Serum potassium levels and longterm post-discharge mortality in acute myocardial infarction. Int $\mathrm{J}$ Cardiol 2014;172:e368-e370.

6. Tada Y, Nakamura T, Funayama H, Sugawara Y, Ako J, Ishikawa SE, et al. Early development of hyponatremia implicates short-and longterm outcomes in ST-elevation acute myocardial infarction. Circulation J. 2011;75(8):1927-33.

7. Rogers WJ, Frederick PD, Stoehr E, et al. Trends in presenting characteristics and hospital mortality among patients with ST elevation and non-ST elevation myocardial infarction in the National Registry of Myocardial Infarction from 1990 to 2006. Am Heart J. 2008:156(6):1026-103419032996

8. Krogager ML, Eggers-Kaas L, Aasbjerg K, Mortensen RN, Kober L,
Gislason G, Torp-Pedersen C, Sogaard P. Short-term mortality risk of serum potassium levels in acute heart failure following myocardial infarction. Eur Heart J CVP 2015;1:245-251.

9. Macdonald JE, Struthers AD. What is the optimal serum potassium level in cardiovascular patients? J Am Coll Cardiol. 2004;43(2):15516114736430

10. Shlomai G, Berkovitch A, Pinchevski-Kadir S, et al. The association between normal-range admission potassium levels in Israeli patients with acute coronary syndrome and early and late outcomes. Medicine (Baltimore). 2016;95(23):e3778.

11. Colombo MG, Kirchberger I, Amann U, et al. Admission serum potassium concentration and long-term mortality in patients with acute myocardial infarction: results from the MONICA/KORA myocardial infarction registry. BMC Cardiovasc Disord. 2017;17(1):198. Published 2017 Jul 24. doi:10.1186/s12872-017-0635-x

Copyright: () the author(s), 2019. It is an open-access article distributed under the terms of the Creative Commons Attribution License (CC BY 4.0), which permits authors to retain ownership of the copyright for their content, and allow anyone to download, reuse, reprint, modify, distribute and/or copy the content as long as the original authors and source are cited.

How to cite this article: Meghwal K. A Study to Evaluate the Role of Hypokalemia in Acute Myocardial Infarction Patients: A Prospective Hospital Based Study. Asian J. Med. Res. 2019;8(2):ME01-ME03.

DOI: dx.doi.org/10.21276/ajmr.2019.8.2.ME1

Source of Support: Nil, Conflict of Interest: None declared.

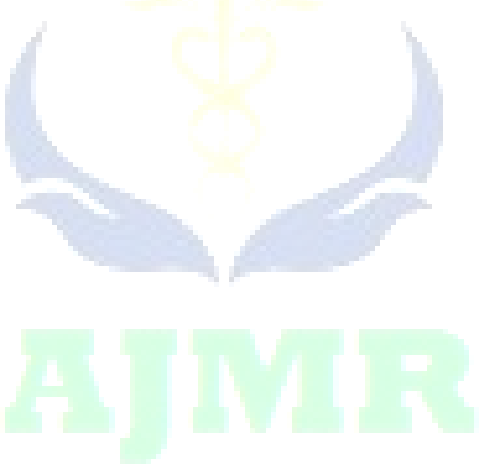

